\title{
FILIA PIRATAE: UNA PROPUESTA PARA LA ACTUALIZACIÓN DE LA ENSEÑANZA-APRENDIZAJE DEL LATÍN PARA HISPANISTAS
}

\author{
María Elena Curbelo Tavío \\ Universidad de Las Palmas de Gran Canaria
}

\section{RESUMEN}

En este artículo presentaremos el uso que se puede hacer del texto medieval Filia piratae, recogido en los Gesta Romanorum (1342), para enseñar latín en el contexto universitario. Filia piratae forma parte de una colección de ejemplos moralizados destinados, en su origen, a ser empleados por los predicadores en sus sermones. A ello se debe el latín simplificado de la anécdota que se relata, cuya sencillez y cercanía al español nos sirve como mecanismo de motivación para acercar los contenidos grecolatinos y la tradición clásica a los alumnos de las titulaciones de Lengua y Literatura Española, en las que la asignatura de Latín a menudo se limita a un semestre. Otro de los aspectos notables del relato es que se trata de uno de los pocos, en esta época, en el que la mujer se convierte en protagonista y toma la palabra. Es, por tanto, un texto muy interesante para trabajar la consideración de la mujer a lo largo de la historia como un elemento transversal dentro de los estudios de Filología Hispánica, en los que la perspectiva de género está cobrando gran importancia.

Palabras Clave: Latín, La hija del pirata, Filia piratae, Lengua Española y Literaturas Hispánicas, textos latinos.

\section{FILIA PIRATAE: A PROPOSAL TO UPDATE THE TEACHING AND LEARNING OF LATIN FOR HISPANISTS}

\section{Abstract}

In this paper, we will be showing how we can use the medieval text Filia piratae, included in the Gesta Romanorum (1342), to teach Latin at the University. Filia piratae is part of a collection of moralising examples originally designed to be used by preachers in sermons. Since the anecdotes in the text are told in a simplified Latin language, somehow similar to Spanish, the choice of this text in the classes of Latin for students of Spanish Studies is motivating as its study contributes to introduce Greco-Roman contents and classical tradition in subjects of the Degree in Spanish Language and Literature that often teach Latin in just a semester. Likewise, another relevant aspect of this story is that women acquire a protagonist role and have a word to say. Therefore, this is a very suitable text to analyse the consideration of women throughout history since gender studies as a tranversal issue in the domain of Hispanic Philology is gaining more importance.

KeYwords: Latin, Filia piratae, Spanish Studies, Spanish Language and Literature, Latin texts. 


\section{INTRODUCCIÓN}

Nos gustaría iniciar este artículo con una pregunta: ¿debe circunscribirse la enseñanza del latín, en la universidad, a los textos clásicos canónicos, sobre todo cuando se imparte para alumnado que no pertenece a la titulación de Filología Clásica sino a las titulaciones de Lengua Española y Literaturas Hispánicas? A nosotros nos parece que no y por eso, en este trabajo, presentaremos una manera diferente de enseñar latín a partir de otro tipo de textos, en concreto, del relato medieval Filia piratae, La hija del pirata, recogido en los Gesta Romanorum (1342), una colección de ejemplos moralizados destinados, al menos en sus inicios, a su uso por los predicadores en los sermones.

Los inconvenientes con los que el profesorado universitario de lenguas y cultura clásica nos encontramos son fundamentalmente dos: 1) por un lado, Latín suele ser una asignatura de muy pocos créditos, por lo que el tiempo del que disponemos para su impartición es escaso; y 2) por otro lado, gran parte del alumnado que accede a nuestros cursos carece de los conocimientos mínimos imprescindibles para la traducción e interpretación de los textos clásicos, dado que no ha cursado Latín en bachillerato.

Ambos condicionantes obligan al docente a plantear un cambio en la didáctica del Latín, pero también ofrece la posibilidad de convertir lo que en principio podrían ser dificultades en una oportunidad. Nuestro objetivo primordial ya no puede ser el de enseñar, exclusivamente, los contenidos y la gramática clásicos, sino uno más pragmático, el de proporcionar a los discentes los conocimientos necesarios de latín que los doten de una preparación adecuada para el estudio diacrónico del español, así como ponerlos en disposición para que más adelante puedan, con la ayuda de una edición bilingüe y con fluidez, interpretar correctamente los textos latinos de nivel medio. De este modo, el alumnado puede ver la asignatura de Latín como algo práctico de cara a su futuro académico y profesional.

Partimos de la necesidad de vincular los conocimientos adquiridos en la asignatura de Latín con las materias de la titulación en la que se encuentra integrado, sobre todo con aquellas relacionadas con el estudio de la diacronía del español, con los estudios literarios y culturales y con la tradición clásica. Pero también, de la obligación de optar por textos más cercanos al estado de la lengua española desde el punto de vista gramatical y léxico y que respondan a intereses más próximos a los estudiantes ${ }^{1}$, como sucede con el relato de La hija del pirata.

${ }_{1}$ Son varios los trabajos que se han dedicado tanto a la metodología de la enseñanza del latín como a la necesidad de incluir la transversalidad en el currículum, ya sea en la educación secundaria como en la superior. Gutiérrez Galindo (1995) y Meynet (2013), entre otros, formulan en sus artículos una crítica a la enseńanza tradicional del latín; precisamente, la inclusión de nuevos métodos en el aprendizaje de esta lengua son los que nos proponen, en sus artículos, Abbott, Davis y Gascoyne (1998) y Alcalde y Gómez (2000); sobre la transversalidad en la educación superior, puede leerse Botero (2006); y una aplicación de la transversalidad a la didáctica del Latín se encuentra en Arcos Pereira y García de Paso (1999). 
El texto que denominamos Filia piratae o La hija del pirata está recogido, bajo el epígrafe De sectanda fidelitate (Sobre el compromiso de fidelidad) ${ }^{2}$, en el volumen titulado Gesta Romanorum, obra anónima ${ }^{3}$ que ofrece, en latín, una colección de cuentos, fábulas, anécdotas, leyendas, historias clásicas, etc., provenientes de diversas fuentes y con una función moralizadora, de la que se servían los profesores, oradores y predicadores en general para adornar su exposición, con el fin tanto de ofrecer un relato que, a modo de ejemplo les sirviese para adoctrinar, como para que sus ideas fueran captadas más fácilmente por un auditorio generalmente ignorante (Herrtage 1962: viII). Para alcanzar estos objetivos, se empleaba un latín muy sencillo y simplificado.

Cada una de las 181 historias que forman parte de los Gesta Romanorum ofrece, además del texto, presentado bajo la forma de exemplum y precedido por un título y el número del capítulo, una aplicación moral que aparece bajo los subtítulos de moralisatio, applicatio, expositio o mystice; incluso, otras veces, se muestra directamente sin epígrafe tras el texto (De la Torre y Lozano Escribano 2004: 5).

Este tipo de compilaciones de exempla estaban destinadas a proporcionar a los estudiantes material de apoyo para la redacción de sus discursos y a los oradores para la exposición de estos. Entendemos los exempla como una figura retórica en la que se presentan hechos que han sucedido de manera semejante o contraria a aquellos que se están exponiendo o palabras de una auctoritas, cuya finalidad es embellecer el discurso, enseñar y persuadir. Formaban parte de la educación tanto del joven griego como del romano, pues los exempla, unos históricos y otros legendarios, se presentaban como modelos de conducta (Brémond, Le Goff y Schmitt 1982: 43-48; Harto Trujillo 2011: 511; Marrou 1985: 306).

Este no es un recurso novedoso, pues está presente desde la Antigüedad clásica. Rétores y oradores como Aristóteles (Rhet.1356b, 1357b), Cicerón (inv. 1.49.6), el autor de la Rhetorica ad Herennium (Rhet.Her. 4.62) o Quintiliano (inst. 5.11) se servían de esta figura retórica en sus discursos y destacaban su importancia en sus preceptivas. En la Edad Media, estos exempla, compuestos a menudo por parábolas e historietas, se integraron en los sermones y en la literatura religiosa y adquirieron un marcado carácter moralizador y edificante (Brémond, Le Goff y Schmitt 1982; De la Torre y Lozano Escribano 2004: 21-28; Harto Trujillo 2011: 509-510; Welter 1927) ${ }^{4}$.

2 Para el texto latino nos servimos de la edición realizada por Oesterley (1872); para la traducción, de la elaborada por De la Torre y Lozano Escribano (2004).

${ }^{3}$ En el estudio previo a la edición y traducción de los Gesta Romanorum, De la Torre y Lozano Escribano (2004: 20-21) ofrecen un apartado dedicado a la autoría, lugar y fecha de la primera versión de la obra. Sobre ello puede también leerse en la edición de los Gesta que efectúa Herrtage (1962: IX-XIII).

${ }^{4}$ Harto Trujillo (2011) ofrece en su artículo un exhaustivo estudio sobre la definición y el uso del exemplum según las retóricas desde la Antigüedad hasta el Renacimiento; en cambio, Welter 
Un ejemplo de lo anterior es, precisamente, la colección de los Gesta Romanorum, que fue desde su inicio ampliamente difundida. Su éxito fue tal que constituyó la fuente, directa o indirectamente, de una parte importante de la literatura posterior, hasta el punto de que encontramos la huella de los relatos aquí compilados en autores de la talla de Boccaccio, Chaucer o Shakespeare (Herrtage 1962: XVIII; Encyclopaedia Britannica 2013).

El texto de La hija del pirata es uno de estos exempla. En él se narra la captura de un joven por unos piratas. Su liberación depende del rescate que ha de pagar su padre al jefe de los corsarios y que el chico solicita a su progenitor a través de una carta; este, sin embargo, harto de la mala cabeza de su hijo, se niega a ello. El muchacho permanece un tiempo debilitándose en la cárcel y solo, salvo en los momentos en los que acude a visitarlo y a proporcionarle algo de alimento la hija del jefe de los piratas. La muchacha accede a liberarlo con una única condición: que se la lleve de allí y se case con ella. El joven accede y ambos ponen rumbo a la casa del padre del chico. Sin embargo, su progenitor alega múltiples razones por las que el hijo no debe casarse con la hija del pirata. A cada premisa, la joven contraargumenta de una forma tan inteligente que al padre no le queda más remedio que aceptar la boda.

La trama presentada en La hija del pirata, o De sectanda fidelitate, si usamos la rúbrica con la que aparece en los Gesta, no es original, pues tiene su precedente en la Controversias 1.6 de Séneca (c. 37 d.C. $)^{5}$.

El texto de Séneca, titulado Archipiratae filia, La hija del jefe de los piratas ${ }^{6}$, ofrece, al igual que el relato posterior recogido en los Gesta, un argumento similar al de las novelas rosas actuales y a los de la Comedia Nueva, pero, además, presenta elementos que son tópicos de las controversias, tales como los piratas, el rapto, la petición de rescate mediante una carta y el desheredamiento del hijo (Adiego Lajara, Artigas Álvarez y Riquer Permanyer 2005: 151 n.57; Marrou 1982: 266; Bonner 1984: 409-410; Clark 1977: 231-232).

(1927) y Brémond, Le Goff y Schmitt (1982) centran su estudio en la extensión del exemplum en la literatura religiosa y didáctica de la Edad Media.

5 Este, que aparece como el capítulo 5, no es el único exemplum que tiene su procedencia en las Controversias de Séneca (c. 43 a.C.- c. 37 d.C.) dentro de los Gesta. También tienen su origen en los textos declamatorios del autor hispano los relatos 2, 3, 4, 6, 7, 14, 73, 90, 100, 112, 116 y 134. En las Declamaciones menores 257, atribuidas a Quintiliano, se presenta un relato similar al de contr.1.6 aunque, en este caso, es el padre el que es raptado por los piratas y su hijo, pobre, el que debe pagar el rescate. El dinero lo consigue gracias a un acuerdo con un rico enemigo del padre, quien, a cambio de proporcionarle el rescate, le concede la mano de su hija en matrimonio. Una vez liberado, el padre pide al muchacho que se divorcie, pero este rehúsa y su padre lo repudia (Bonner 1984: 409).

6 Para la traducción nos servimos de la realizada para la Biblioteca Clásica Gredos, en 2005, por Adiego Lajara, Artigas Álvarez y Riquer Permanyer. 


\section{USO DIDÁCTICO}

El carácter didáctico del texto de La hija del pirata se encuentra en sus orígenes, pues no solo los Gesta Romanorum tenían una naturaleza pedagógica, sino que el género de las controversias, en el que hunde sus raíces el relato, es, dentro de las declamaciones, un tipo de texto eminentemente didáctico.

La controversia es un tipo de ejercicio dedicado a los oradores que se querían especializar en los discursos judiciales. Tal y como explican Adiego Lajara, Artigas Álvarez y Riquer Permanyer (2005: 24) en su introducción a la traducción de las Controversias de Séneca:

Se trata, esencialmente, de someter causas ficticias y controvertidas al arbitrio de un tribunal mediante la elaboración de un discurso legal. El tema que para ello se propone debe tratarse en el marco que trazan la presentación de una situación particular y el concurso de una o más leyes.

Los rétores enseñaban a sus alumnos, a través de ejemplos, toda la casuística susceptible de darse en un juicio y a enfrentarse a ello tanto en su papel de acusador como de defensor. Para complementar esta práctica, los preceptores se servían de casos simulados en los que, tras exponer la ley que regía dicho ejercicio, se proponía una situación en la que el protagonista era acusado y sus acciones denunciadas, apoyadas o excusadas. Esta forma de ejercicio declamatorio fue el origen de las controversias (Bonner 1984: 402; Clark 1977: 228-233).

Aunque el objetivo final del futuro abogado es, por tanto, la práctica a través de alegatos ficticios, los profesores helenistas no solo ofrecen a sus alumnos ejemplos extraídos de los libros de texto, sino casos fantásticos. En palabras de Marrou (1982: 266), «casos absurdos en que se aplican leyes pintorescas, forjadas para las circunstancias: no hay más que tiranos, piratas, raptos, violaciones, hijos desheredados en condiciones inverosímiles», más propios de una comedia de enredos que de la elocuencia judicial? .

En las escuelas de gramática, el profesor pedía al alumno que escribiese un discurso sobre un tema determinado, discurso que, a posteriori, podía ser declamado en voz alta y públicamente. En este ejercicio retórico, las controversias constituían un ejercicio de razonamiento dialéctico importante (Kennedy 1972: 312 y ss.).

La controversia, dentro del ejercicio declamatorio, se configuraba como «una especie de lucha entre dos adversarios que, ante el público, defienden tesis opuestas» (Rey 2012: 346) pero, además, era una actividad valiosa para poner a prueba el ingenio de los estudiantes. Los casos en ella planteados son ficticios y, en muchas ocasiones, los argumentos con los que justificar la posición que ante ellos se adoptaba tenía, más un carácter moral que lógico o razonable (Murphy 1989: 135; 250).

${ }^{7}$ Bonner (1984: 402-425) ofrece el repertorio de los temas más usuales empleados en este tipo de ejercicios a partir del estudio de las Controversias de Séneca y de las Declamaciones menores de Ps-Quintiliano. 
En la controversia 1.6 de Séneca, La hija del jefe de los piratas, sobre la que luego se desarrolla el texto que nosotros trabajamos, se ofrecen distintos puntos de vista, según se argumente a favor del padre del muchacho o de la joven (sententia); igualmente se formulan preguntas sobre el modo de actuar de los personajes para saber si este es lícito, esto es, se ajusta a la legalidad, o ético, es decir, se trata de un modo de proceder acorde a la moral (diuisio); y, finalmente, se exponen los diferentes modos de acercarse al caso $\left(\right.$ colores $^{8}$, intentando adjudicar una interpretación desfavorable al argumento del contrario y favorable al propio como, por ejemplo: lo que movía a la doncella no era la compasión sino la lujuria, por lo que su acción, desde la óptica de la moralidad, no era válida; ella no se había marchado con el joven por amor a él, sino por odio a su padre; el jefe de los piratas estaba en connivencia con su hija; o el padre del joven lo que realmente temía era que la muchacha fuera una espía del jefe pirata.

En nuestras clases no trabajamos específicamente la controversia como género literario, aunque sí mostramos que el texto utilizado tiene en ella su origen, por lo que creemos necesario que se conozcan algunos aspectos básicos de este género e insistimos en su uso moralizante, presente no solo en las Controversias de Séneca sino en la compilación de los Gesta Romanorum.

Por otro lado, tanto la trama como los personajes de La hija del pirata se prestan a considerar esta historia, sin serlo, una especie de breve novela amorosa, lo que nos da pie para mencionar los diferentes tipos de novelas, poniendo especial atención en aquellas que hunden sus raíces en el mundo clásico o que reciben gran influencia de este, como es la novela pastoril, con un claro precedente en La historia etiópica, de Heliodoro; en Dafnis y Cloe, de Longo de Lesbos o en Las bucólicas, de Virgilio; la novela de caballería, en cuyo germen, lo mismo que en el de los cantares de gesta, se encuentran La Iliada, La Odisea y La Eneida, o incluso en la novela picaresca, heredera de Petronio, de Apuleyo o de Luciano de Samósata (Lida de Malkiel 1951; Signes 2005: 382-387; 461-466).

Ya se ha señalado que los casos ficticios que los profesores de elocuencia proponían a sus alumnos estaban repletos de aventuras y personajes quasi románticos hasta el punto de inspirar recopilaciones como los Gesta Romanorum o novelas medievales, tanto en latín como en lengua vernácula, y que se convirtieron en fuente de la tradición novelística de las literaturas modernas, sobre todo de la inglesa (Marrou 1982: 370).

Pero además de la novela, y como ya se mencionó anteriormente, el argumento de este breve relato contiene elementos propios de la Comedia Nueva de época

${ }^{8}$ Las controversias de Séneca presentan siempre la misma estructura: tras el argumento de la controversia, hay una selección de sententiae, oraciones y comentarios ingeniosos, elegantes, agudos o brillantes de importante valor para la defensa de una causa; una discusión sobre la diuisio, estructura que se adopta para organizar los argumentos de un caso y que aparecen bajo la forma de quaestiones o preguntas y que Murphy (1989: 250) denomina la «solución del profesor»; y una antología de colores, diversas maneras en las que se puede acercar a un caso dependiendo de la causa (Adiego Lajara, Artigas Álvarez y Riquer Permanyer 2005: 26-29: Kennedy 1972: 324-326; Murphy 1989: 250). 
helenística, un teatro de temática menos mitológica y más cultural, y en el que se reflejaban las costumbres y la vida cotidiana. Los motivos tomados por los autores, cuyo principal representante fue Menandro, eran la violación de una muchacha, el abandono de niños, reconocimiento después de muchos años y avatares, y múltiples intrigas (Lesky 1983: 672-695).

Finalmente, el texto de La hija del pirata se presta para tratar el debate y la argumentación. No en vano, toda la última parte del relato es una presentación de las razones que el padre del joven ofrece en contra del matrimonio y las contraargumentaciones aducida por la muchacha a favor de la boda:

«Hijo, te digo que no puedes confiar en ella y, por tanto, de ningún modo puedes desposarla», replicó el padre. «Engañó a su propio padre cuando te liberó de la cárcel sin su conocimiento, ya que por causa de esa liberación su padre perdió mucho dinero que hubiera podido conseguir por tu rescate [...]. Existe, además, otra razón. Si bien ella te liberó, lo hizo inducida por la lujuria para poder disfrutarte como hombre [...]. Al oír estas razones, intervino la joven: «Respondo a la primera recriminación, cuando afirmas que yo engañé a mi propio padre, que no es verdad. Es engañado aquel que sufre quebranto en algún bien; mi padre, en cambio, es tan rico que no necesita ayuda de nadie [...]. Además, si mi padre hubiese recibido el rescate por él, no hubiera sido mucho más rico por ello y, en cambio, tú habrías empobrecido por el pago del rescate. Por tanto, con esta acción a ti te libré de pagar el rescate y a mi padre no le ocasioné perjuicio alguno. A la segunda incriminación, a saber, que yo lo hice por lujuria, respondo que no puede ser verdad de ningún modo, pues el deseo insano está motivado por la belleza, por la riqueza, por los honores o por la fortaleza. En cambio, tu hijo no tenía ninguna de estas cualidades, pues su hermosura había desaparecido con la cárcel; ni era rico, desde el momento en que no tenía con qué redimirse a sí mismo; ni fuerte, pues la cárcel había debilitado su fortaleza. Por consiguiente, únicamente me movía la piedad para liberarlo». El padre, después de oír los anteriores razonamientos, no pudo seguir argumentando más (De la Torre y Lozano 2004: 76).

El uso didáctico del relato de La hija del pirata no se limita al aspecto literario. Este texto, aparentemente sencillo en cuanto al contenido, nos permite:

1. Que el alumnado se enfrente al latín con mayor motivación y facilidad, pues el texto propuesto presenta una lengua muy cercana al espańol y un argumento relacionable con cuentos o leyendas infantiles e, incluso, como acabamos de mencionar, con ciertas novelas de temática amorosa, con las comedias y con los textos argumentativos.

2. Trabajar prácticamente la totalidad de las nociones gramaticales, pues en el texto seleccionado se pueden estudiar voces, modos y tiempos de los verbos, verbos irregulares, verbo sum y sus compuestos, formas no personales del verbo, empleo del vocativo, pronombres y determinantes, formación del adverbio, grados del adjetivo, uso de los nexos polivalentes, cuestiones de sintaxis como las oraciones de relativo, las condicionales, las causales, las interrogativas y exclamativas, tanto directas como indirectas, o el ablativo absoluto. 
Un ejemplo de lo expuesto se puede apreciar en el siguiente fragmento:

Accidit quodam die, quod, cum puella eum visitaret, ait iuvenis ei: «O bona puella, utinam velles pro mea liberatione laborare!» Quae ait: «Quomodo potero hoc attentare! Pater tuus, qui te genuit, non vult te redimere, ego vero, cum sim tibi extranea, quomodo deberem hoc cogitare! Et si te liberarem, offensionem patris mei incurrerem, quia tuam redemptionem perderet pater meus. Verumtamen mihi unum concede, et liberabo te» (Oesterley 1872: 278).

Específicamente, con este texto, relacionado con el verbo podemos ver las formas no personales (laborare, attentare, redimere, cogitare) y personales en modo indicativo (accidit, ait, potero, genuit, vult, liberabo), subjuntivo (visitaret, velles, sim, deberem, liberarem, incurrerem, perderet) e imperativo (concede); además, se pueden estudiar las variantes temporales, puesto que hay presentes, pasados y futuros, así como las diferencias de conjugación entre verbos regulares e irregulares; tampoco faltan los defectivos.

En el apartado nominal encontramos pronombres indefinidos (unum), anafóricos (eum, ei), deícticos (hoc), personales (ego, me, mihi, te, tibi) y relativos (qui); adjetivos posesivos (meus, mea, mei, tuam) e indefinidos (quodam). Incluso podemos insistir en que, a veces, aparecen los llamados falsos relativos o relativos de coordinación (Quae ait).

Respecto a las oraciones, nos permite introducir a los alumnos en las distintas modalidades de frases, pues en este ejemplo hay oraciones enunciativas (Accidit quodam die...), desiderativas (utinam velles...), expresivas (Quomodo potero...) e impresivas (mihi unum concede). Igualmente, se observan diferentes clases de subordinadas, como las condicionales (si te liberarem), las causales (cum sibi extranea, quia tuam redemptionem perderet), las de cum histórico o causal-temporal (cum puella eum visitaret) y la completiva introducida por quod, que se convertirá en un nexo casi universal sustituyendo a otras construcciones, más usuales en el latín clásico, introducidas por $u t$ o sin ningún nexo, como las de acusativo más infinitivo. Aunque estas últimas no aparecen en el fragmento, se explican con ejemplos extraídos de otros textos.

3. Igualmente, con él se pueden tratar cuestiones relacionadas con el léxico, por otro lado, bastante sencillo, tales como las expresiones para indicar la edad (viginti annos in etate sua compleverat) o las fórmulas diferentes que tenía el latín para pedir y dar en matrimonio según se tratase de una mujer (nubere) o de un hombre (uxorem ducere), aludiendo a la propia ceremonia del matrimonio; además, se pueden estudiar, a partir de él, nociones de acentuación y de etimología, fundamentales para la ampliación del léxico, así como los procesos de evolución fonética producidos a lo largo de la historia del latín como, por ejemplo, la simplificación de geminadas (promitto, opportuno), la monoptongación del diptongo ae (que, etate, sepius), la sonorización de las oclusivas sordas (nutrita, peto...) y la pérdida de las sonoras (veinte, de viginti), los cambios de vocalismo (pido, de peto, 
prometo, de promitto), las síncopas (posible, de possibile), las disimilaciones (encarcelado, de incarceratum), etc.

En este otro fragmento se puede observar parte de lo comentado:

Ille, qui eum in vinculis habebat, quandam pulchram filiam ac oculis hominum gratiosam genuerat, que nutrita in domo erat quousque viginti annos in etate sua compleverat, quae sepius incarceratum visitatum ivit ac consolabatur. [...] Ait ille: "O bona puella, pete a me quid tibi placuerit! Si mihi est possibile, ego concedam». At illa: «Nihil aliud peto pro tua liberatione, nisi quod me in uxorem ducas tempore opportuno». Qui ait: «Hoc tibi firmiter promitto». Statim puella patre ignorante ipsum a vinculis liberavit et eum eo ad patriam suam fugit (Oesterley 1872: 278).

Sobre la acentuación, a partir del texto indicamos la diferencia existente entre sílabas largas y breves por posición y por naturaleza, así como la tendencia del latín a las palabras llanas, aunque, cuando la penúltima sílaba es breve, el acento se retrotrae a la antepenúltima, como sucede en oculis y vinculis frente a opportuno, promitto e ignorante.

En cuanto al léxico, además de ocuparnos de la etimología de palabras españolas, distinguimos entre los vocablos de la lengua culta como oculista, de oculus, filial, de filia, doméstico, de domum, pulcra, de pulchra, vincular, de vinculum o uxoricidio, de uxor, frente a otras de uso cotidiano como pedir, de petere, prometer, de promittere, visitar, de visitare o liberación, de liberatio.

Los aspectos reseñados en los apartados 2 y 3 no se enseñan de forma aislada, sino que, al hilo de la traducción, se explican los contenidos, reforzados con la revisión de otros fragmentos similares del texto de La hija del pirata. Por ejemplo, cuando aparece cum puella eum visitaret, contrastamos con otros cum históricos que ya se han analizado o que se encontrarán.

Otra manera de reforzar estos contenidos es animando al alumno a la creación de textos similares con el léxico que se le proporciona y así, por ejemplo, debe crear una estructura igual a cum puella eum visitaret con iuvenis, puella y uxorem ducere.

4. Mostrar aspectos históricos y literarios cuyo conocimiento es imprescindible para entender la sociedad y las circunstancias de la época clásica y convertir lo que era realia en el mundo clásico en el estudio de aspectos culturales presentes en el texto como el origen del matrimonio y la herencia clásica en la liturgia y la celebración actual, o el patriarcado, por citar solo dos de ellos. De igual manera, nos es útil para trabajar los géneros discursivos, con especial insistencia en la argumentación y la refutación, tal y como ya mostramos en un ejemplo anterior en el que la hija del pirata da al padre del joven protagonista variados argumentos a favor de su boda.

5. Vincularlo con otras asignaturas de los grados, principalmente con aquellas relacionadas con historia de la lengua española y con la literatura y la crítica textual, pues La hija del pirata mantiene lazos estrechos, como estamos demostrando, con el debate y la controversia, pero también con la novela 
rosa actual y la comedia. En este relato, como se puede ver en el ejemplo que se presenta a continuación, encontramos el estilo directo propio de la comedia y de los géneros discursivos, pero, como las novelas, junto al estilo directo hay también una parte narrativa:

Cum vero ad patrem suum venisset, ait ei pater: «O fili, de tuo adventu gaudeo. Sed dic mihi, qualis est ista puella, quam tecum duxisti? » Ait ille: «Filia regis est, quam in uxorem habeo». Ait pater: «Sub pena amissionis hereditatis tue nolo, ut eam in uxorem ducas». Ait ille: «O pater, quid dicis? Plus ei teneor, quam tibi. Quando captus eram in manus inimici et fortiter vinculatus, tibi pro mea redemptione scripsi, et noluisti me redimere. Ipsa vero non tantum a carcere, sed a periculo mortis me liberavit; ideo eam in uxorem ducere volo». Ait pater: «Fili, probo tibi, quod non possis in eam confidere, et per consequens nullo modo in uxorem ducere.» [...] Puella audiens istas rationes ait: [...] «sola pietas me movebat, quod ipsum liberavi.» Pater hoc audiens non potuit filium arguere ulterius. Filius ergo cum magna solemnitate eam in uxorem duxit et in pace vitam finivit (Oesterley 1872: 279).

6. Pero el legado del mundo romano en la cultura occidental no solo se encuentra en la lengua, la literatura, las instituciones y las costumbres, sino que también compartimos muchos de sus valores. Cuatro de esos valores, al menos, los podemos trabajar a partir del texto: fortitudo, un valor relacionado con la acción; fides, valor que rige el comportamiento con los demás; y consilium y prudentia, valores relacionados con la inteligencia (Arcos Pereira y García de Paso 1999: 116-129)'.

7. Y, finalmente, trabajar un elemento transversal básico como es la perspectiva de género, pues uno de los aspectos notables del relato es que se trata de uno de los pocos, en esta época, en los que la mujer se torna en la protagonista y toma la palabra, erigiéndose, además, en la persona más juiciosa e inteligente de la historia. Recordaremos, para ello, la situación secundaria que ha tenido la mujer en sociedades anteriores ${ }^{10}$. Se convierte así en un texto muy interesante para tratar la consideración de la mujer a lo largo de la historia como un elemento transversal dentro de los estudios de Filología Hispánica en los que la perspectiva de género está cobrando gran importancia.

\section{CONCLUSIONES}

En conclusión, la asignatura de Latín, planteada de esta manera, contribuye al perfil profesional del título en cuanto que permite ahondar en el conocimiento de las raíces del español, así como adquirir herramientas y recursos necesarios para

9 Sobre los valores romanos, puede leerse Arcos Pereira y García de Paso (1999).

${ }_{10}$ El papel de la mujer en el mundo antiguo y medieval ha sido ampliamente estudiado, entre otros, por autores como Archer (2001), Cantarella (2002) o Pomeroy (1990). 
abordar, con cierta profundidad, el estudio de fuentes lingüísticas y literarias. A esto hay que añadir que los resultados del aprendizaje están siendo muy favorables, pues el latín simplificado de la anécdota que se relata en La hija del pirata, así como su sencillez y cercanía al español, sirven como mecanismo de motivación. Además, afianza los conocimientos adquiridos en las asignaturas de tradición clásica.

A lo anterior hay que sumar la contribución del latín, enseñado de esta forma, a la adquisición de unas competencias específicas, estrechamente relacionadas con los grados provenientes de las filologías Hispánicas y Románicas, como son el conocimiento de la lengua española y de sus variantes, la capacidad para el uso instrumental de la lengua española y la capacidad para relacionar el conocimiento filológico con otras disciplinas del conocimiento.

Al mismo tiempo, permite al alumnado adquirir conocimientos lingüísticos y culturales latinos que posteriormente podrán aplicar a la correcta traducción al español de un texto latino; obtener conocimientos básicos del latín medieval como preparación para el estudio diacrónico del español; y, finalmente, reconocer y analizar la evolución diacrónica del latín al español.

Recibido: marzo de 2019; ACeptado: junio de 2019. 


\section{BIBLIOGRAFÍA}

Adiego Lajara, Ignacio J., Esther Artigas Álvarez y Alejandra Riquer Permanyer (2005): Séneca El Viejo. Controversias, Madrid: Gredos.

Аввотт, Martha, Sally Davis, y Richard Gascoyne (1998): «National Standards and Curriculum Guidelines", en Richard A. LAFLeuR (ed.), Latin for the 21st Century: From Concept to Classroom, Glenview (Illinois): Scott Foresman-Addison Wesley, 44-58.

Alcalde, Alfonso y Diosdado Gómez (2000): «La necesidad de renovación didáctica de las lenguas clásicas: una nueva propuesta metodológica», Estudios Clásicos 118: 95-131.

Archer, Robert (2001): Misoginia y defensa de las mujeres. Antología de textos medievales, Madrid: Cátedra.

Arcos Pereira, Trinidad y M. ${ }^{a}$ Dolores García de Paso Carrasco (1999): «Valores romanos y ejes transversales», Estudios Clásicos 115: 113-139.

Bonner, Stanley F. (1984): La educación en la Roma antigua: desde Catón el Viejo a Plinio el Joven, Barcelona: Herder.

Botero Chica, Carlos Alberto (2006): «Los ejes transversales como instrumento pedagógico para la formación en valores», Revista Politécnica 3: 49-59.

Brémond, Claude, Jacques Le Goff y Jean-Claude Schmitt (1982): «L'exemplum», Typologie des sources du Moyen Age occidental, Turnhout: Brepols.

Cantarella, Eva (2002): La calamidad ambigua: condición e imagen de la mujer en la antigüedad griega y romana, Madrid: Ediciones clásicas.

Clark, Donald L. (1977): Rhetoric in Greco-Roman Education, Nueva York: Greenwood Publishing Group.

De la Torre, Ventura y Jacinto Lozano Escribano (eds.) (2004): Gesta Romanorum. Exempla europeos del siglo XIV, Madrid: Akal.

EnCyClopaedia BRITANnica (2013): «The Gesta Romanorum». URL: https://www.britannica.com/ topic/Gesta-Romanorum; 29/01/2019.

Gutiérrez Galindo, Marco A. (1995): "Algunas deficiencias estructurales en los métodos tradicionales de enseñanza del latín», en V. Valcárcel (ed.), Didáctica del Latín. Actualización científico-pedagógica, Madrid: Ediciones Clásicas, 65-85.

Harto Trujillo, M. ${ }^{2}$ Luisa (2011): «El exemplum como figura retórica en el Renacimiento», Humanitas 63: 509-526.

Herrtage, Sidney y John Hervon (1962): The early English versions of the Gesta Romanorum, London: Oxford University Press.

Kennedy, George A. (1972): The Art of Rhetoric in the Roman World, Princeton, New Jersey: Princeton University Press.

Lesky, Albin (1983): Historia de la literatura griega, Madrid: Gredos.

Lida de Malkiel, M. ${ }^{a}$ Rosa (1951): «La tradición clásica en España», Nueva Revista de Filología Hispánica, 5.2: 183-223. URL: http://dx.doi.org/10.24201/nrfh.v5i2.216; 29/01/2019.

Marrou, Henry-Irenee (1985): Historia de la educación en la antigüedad, Madrid: Akal.

Meynet, Beatriz C. (2013): «Problemas detectados en relación con la enseñanza tradicional del latín», PhaoS - Revista de Estudos Clássicos 13: 65-92. 
Murphy, James J. (ed.) (1989): Sinopsis histórica de la retórica clásica, Madrid: Gredos.

Oesterley, Hermann (ed.) (1872): Gesta Romanorum, Berlín: Weidmann.

Pomeroy, Sara B. (1990): Diosas, rameras, esposas y esclavas. Mujeres en la antigüedad clásica, Madrid: Akal.

Rey, Juan (2012): «Revisión crítica de la historia de la retórica desde los postulados de la comunicación", Ámbitos, 21: 333-360. URL: http://www.redalyc.org/articulo.oa?id=16823120017; 29/01/2019.

Signes, Juan et al. (2005): Antiquae lectiones: el legado clásico desde la antigüedad hasta la revolución francesa. Madrid: Cátedra.

Welter, Jean-Thiébaut (1928): L'exemplum dans la littérature religieuse et didactique du Moyen Âge, París: Occitania. 
